\title{
Fuzzy Expert System for Earthquake Prediction in Western Himalayan Range
}

\author{
Rabia Tehseen, Muhammad Shoaib Farooq*, Adnan Abid \\ Department of Computer Science, University of Management and Technology, \\ Lahore 54770, Pakistan \\ shoaib.farooq@umt.edu.pk
}

\begin{abstract}
Fuzzy Expert System (FES) with application to earthquake prediction has been presented to reproduce the performance of a human expert in earthquake prediction using expert systems. This research aims to predict future earthquakes having a magnitude 5.5 or greater. Previous earthquake data from 2000 to 2019 have been collected for this purpose. Since the earthquake data for the specified region have been reported on different magnitude scales, suitable relationships were determined to obtain uniform data. The uniform data have been used to calculate seismicity indicators according to the guidelines provided by Gutenberg-Richter's scale for quantitative determination of earthquake features. The relationships among these seismic indicators have been used by the human expert to set the rule base of Fuzzy expert system. These rules have been mathematically validated and tested on instrumentally recorded earthquake data. The results obtained from the proposed FES presented $47 \%$ accuracy in predicting future earthquakes that may occur in the $100 \mathrm{~km}$ radial area from $34.708{ }^{\circ} \mathrm{N}, \mathbf{7 2 . 5 4 7 8}^{\circ} \mathrm{E}$.
\end{abstract}

Index Terms-Expert system; Fuzzy logic; Earthquake prediction; Seismic data.

\section{INTRODUCTION}

Earthquake prediction is a highly complicated task and many investigators have used different approaches for making forecasts. Artificial intelligence has emerged in early 1980 's as a distinct discipline for the prediction of earthquakes using seismic data from multiple zones. The application of expert systems (ESs) in the field of earthquake prediction has shown promising results.

Many methods, models, and frameworks have been proposed to highlight the use of ES for earthquake prediction. Multiple types of expert systems, including Fuzzy expert system, rule based expert system, and hybrid expert system, have been examined in the literature to forecast future earthquake from historic as well as instrumental data. A comprehensive review of expert system based approaches used in the literature for earthquake prediction during the past decade has been presented in [1].

In practice, expert systems have been efficiently used for risk analysis and assessment in multiple areas, such as engineering, economics, information technology (IT), and healthcare. Specifically, ESs have been successfully applied for soil classification [2], land sliding hazard assessment [3],

Manuscript received 2 December, 2019; accepted 24 April, 2020.
[4], seismic hazard analysis [5], and earthquake damage evaluation of buildings [6]. Although a lot of active research has been conducted globally, but standardization of earthquake prediction procedures still remained in their infancy stage [7]. Multiple models of expert systems have been proposed in literature, including Fuzzy expert system (FES), Neuro-Fuzzy expert system (NFES), Rule-based expert system (RBES), and Frame-based expert system (FBES) to process geographical information of the multiple region [8]. Many researchers have analyzed combination of artificial neural network and Fuzzy inference system to perform seismic risk assessment in civil engineering [3], [9].

The motivation behind applying expert system technique for earthquake prediction lies in its effectiveness and reliability [10]. ESs have been applied in earthquake engineering for the classification of seismic risk and landslide venerability [11]-[14]. Ionosphere disturbance has been examined to propose a Fuzzy logic based model in [15] by measuring ionosphere change parameters. The research in [16] highlighted the vagueness of the Fuzzy logic by examining the events that cannot be recorded statistically such as, abnormal animal behavior, crack in the underground fault etc. Earthquake damage evaluation has been performed in [17]. The authors in [18] examined earthquake pattern in the Zagros range using Fuzzy rule-based ES model for couple earthquakes. The authors in [19] applied NFES to compute land sliding susceptibility using statistical index approach.

Ahumada et al. [20] proposed a new attenuation relationship based on three Fuzzy input sets, including epicentral distance, earthquake magnitude, and intensity using earthquake dataset of Taiwan and United States of America (USA). The authors in [21] predicted earthquakes on the bases of the classification of seismic signals. Multiple algorithms have been combined for development of hybrid prediction model [22], [23]. Set of rules have been presented for earthquake prediction in [24]. Mirrashid et al. [25] combined grid partition, subtractive clustering, and Fuzzy Cmeans (FCM) for the development of models using NFES structure. ES has been successfully applied for risk assessment in civil engineering [26], landslide susceptibility in seismic hazard analysis and soil classification [27]-[29]. Neuro-Fuzzy model has been used in combination with conservation of energy in angular momentum [30], seismic risk assessment of building and bridges in [31]. Hybrid 
model has been used in [32], [33] to predict seismic subsidence for earthquake prediction. ES has been used to evaluate the ergonomics system of oil refineries in [34].

Before large earthquakes, precursor identification, determination of their mutual relationships, and application of Fuzzy expert system for making long term deterministic forecasts about tentative area, the magnitude and ground shaking intensity of upcoming events is intuitively appealing and could greatly improve the efforts of the Government Departments in issuing early warnings to handle such emergency situations. We intend to apply Fuzzy expert system for prediction of the expected magnitude of earthquakes that might probably occur in the region of $100 \mathrm{~km}$ radial area around $34.708^{\circ} \mathrm{N}, 72.5478^{\circ} \mathrm{E}$ reference point. Our work is novel as according to the best of our knowledge, none of the streams of the expert system has been proposed for earthquake prediction in the specified region. The selected region is recumbent to catastrophic earthquakes due to its geophysical location. Fault lines of Main Boundary Thrust (MBT) and Main Central Thrust (MCT) are joining with Balakot-Bagh fault under this region, which is causing major earthquakes here, but still this zone has been neglected and none of the expert system type has been applied on the dataset of this region to forecast future earthquakes. Aim of the research is to analyze instrumentally recorded seismic data within the specified region through FES to forecast the major earthquake with magnitude 5.5 or greater.

The remaining parts of the article have been arranged as follows. The literature review is given in Section II. Section III covers methodology, where as an analysis is presented in Section IV. Conclusions and future directions are given in Section V.

\section{LITERATURE REVIEW}

Earthquake prediction is one of the highly complicated tasks in the real world. In the past, many evolutionary "Artificial Intelligence" (AI) algorithms have been proposed for earthquake prediction. Expert system (ES) is one of the distinctive approaches of AI that has yielded comparatively better results in forecasting earthquakes. In this section, we have summarized the research work describing the use of an expert system for earthquake prediction.

\section{A. Fuzzy Expert System (FES)}

The concept of Fuzzy logic has been introduced by Zadeh [35]. A Fuzzy expert system accepts input as crisp variables and converts them into Fuzzy variables. Fuzzy inference engine applies the rules suggested by an expert from the knowledge base. Techniques based on Fuzzy logic have the benefits over multiple procedures due to their ability to combine with linguistic variables. These Fuzzy variables would be converted back into the crisp variable to generate output through the process called defuzzification. Fuzzy logic is more suitable in the situations where a greater number of uncertainties have been involved, such as earthquake prediction and in the scenarios, where an approximate but quick solution is required. Fuzzy logic is not a logic that is Fuzzy itself, but a logic that can be used to demonstrate fuzziness [7]. Kamath et al. [16] highlighted the vagueness of the Fuzzy logic and examined the nonstatistical events, such as abnormal animal behavior, radon gas emission, etc. The authors in [20] proposed a new attenuation relationship based upon three Fuzzy input sets using earthquake dataset of Taiwan and USA. A normalized Fuzzy ground motion model has been demonstrated using a rational design tool through a combination of natural language with seismic data statistics to quantify response frequency. The reference [18] studied earthquake pattern in the Zagros range through Fuzzy rule-based model. The proposed model has been evaluated using the Molchan statistical procedure by comparing complicated reasoning procedure of the forecasting model with knowledge simulation provided by human experts using the datasets of Iran. Cai et al. [6] presented a rock burst forecasting model by studying the seismic features of coal mining in China. In this study, Gaussian shaped membership function has been combined with the exponential distribution function using reliability theory. The comprehensive forecasting result was obtained by integrating the maximum membership degree principle (MMDP) and the variable Fuzzy pattern recognition (VFPR) method. The performance of the proposed model has been evaluated using seismic data collected over the period of four months. The proposed model has been able to forecast the rock burst incident in the coal mine of China. Multiple algorithms have been combined for development of the hybrid prediction model [23], [33]. Ratnam et al. [15] examined ionosphere disturbance and have proposed a Fuzzy logic-based gradient descent method to forecast the ionosphere change parameters. The gradient descent estimated values were used to tune the membership function. The satisfactory performance has been observed during evaluation of the proposed model using data collected from two geomagnetic storms on the low latitude.

\section{B. Rule-Based Expert System (RBES)}

In RBES domain, knowledge is represented by a set of rules and the current situation is presented with the set of facts stored in the database. An inference engine is responsible to match the rule with the fact. The fired rule may change the set of facts and add new facts. Many researchers have used rule-based expert system for earthquake prediction. Hossain et al. [10] presented a belief rule based expert system to predict the earthquake under uncertainty. Specific animal behavior in response to environmental and chemical changes has been examined for earthquake prediction. Ikram et al. [24] developed rules from historical earthquake data using predicate logic. These rules have been mathematically validated on real time data. Prediction is performed through RBES that takes current earthquake attributes for prediction of future earthquake.

\section{Neuro-Fuzzy Expert System (NFES)}

Fuzzy logic is combined with neural networks to develop expert systems. Fuzzy logic provided a high-level reasoning procedure by including domain information from the domain expert, and neural network has been used to develop lowlevel computational structures. The Neuro-Fuzzy expert system has been used in many articles to analyze multiple 
aspects of data for making earthquake predictions. Ghorbanzadeh et al. [8] collected geographical information to pass through six different membership functions for measuring land sliding susceptibility using NFES. Many researchers have analyzed combination of artificial neural network and Fuzzy inference system [3], [9], [30]. Andric et al. [17] studied earthquake attribute, such as magnitude, depth, longitude, and latitude to provide input to NFES for computation of the future earthquake.

\section{MethodOLOGY}

The main objective of this study is to identify the relationships among multiple precursors, which may lead the earthquake forecast mechanism, and to develop a Fuzzy expert system for making long-term earthquake predictions about approximate magnitude of the forthcoming devastating within the selected area. Figure 1 presents the proposed Fuzzy expert system that has been trained using data collected from multiple national and international agencies.

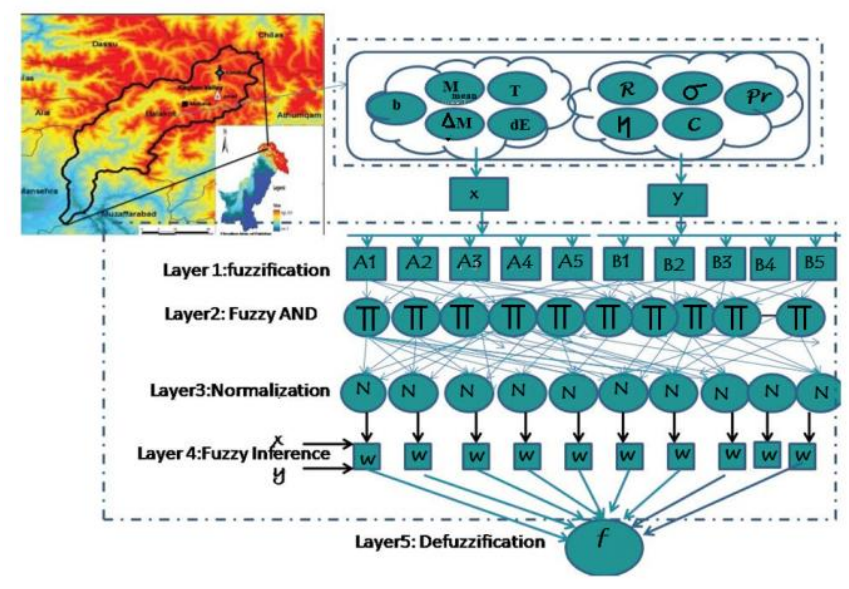

Fig. 1. Methodology of the Proposed Fuzzy Expert System.

Data normalization has been done to ensure uniformity in the parameters extracted through initial data analysis. Set of parameters used to train FES has been given in Table I. The relationships among these parameters have been determined to formulate a rule base and membership functions of FES. The instrumental data have passed through the Fuzzy inference system to infer results regarding the expected magnitude, epicenter, and return period of an upcoming earthquake within the specified zone. Figure 1 presents the methodology used to develop FES in this research.

TABLE I. SET OF SEISMICITY INDICATORS.

\begin{tabular}{|c|c|}
\hline Seismic Indicator & Description \\
\hline $\mathrm{T}$ & Elapsed time \\
\hline $\mathrm{M}_{\text {mean }}$ & Mean magnitude \\
\hline$\sqrt{\mathrm{dE}}$ & Seismic Energy \\
\hline $\mathrm{b}$ value & Slope \\
\hline$\Delta \mathrm{M}$ & Magnitude deficit \\
\hline
\end{tabular}

\section{A. Location}

Geologically, Pakistan is located in the Indus Tsangpo interconnection [14], which is almost $200 \mathrm{~km}$ north side of the Himalayas and can be easily defined by an exposed ophiolite chain along with its southern sides. In this research, we have selected $100 \mathrm{~km}$ radial area from latitude: $34.708^{\circ}$ $\mathrm{N}$, longitude: $72.5478^{\circ} \mathrm{E}$ known as the "Indus-Kohistan seismic zone" covering Tarbela Dam and vicinity. Apparently, some prominent fault lines also pass through this area. Many disastrous earthquakes that caused great loss of life and property had their epicenter in this area.

\section{B. Data Collection}

The most important stage for the development of an earthquake forecasting expert system is the collection of precise data. In this research, we have used the dataset provided by the United States Geological Survey (USGS), International Seismological Centre, United Kingdom (ISC) and Seismic Centre, Tarbela Dam Project, Pakistan. We have used these datasets from international and national sources due to their reliability and accuracy because data accuracy and its abundance has fundamental importance in the development of earthquake predicting expert systems.

\section{Data Extraction and Synthesis}

After collecting data from the specified zone, multiple parameters have been determined. These parameters have been divided into two distinct sets: $\mathrm{x}$ and $\mathrm{y}$. Set $\mathrm{x}$ contains the parameters that have been directly extracted from the dataset. Whereas set y contains the parameters derived from the dataset after manipulation of multiple formulas.

\section{Seismicity Indicators}

To evaluate the seismic potential of a region, five mathematically defined seismic parameters have been used. These are called seismic indicators. They include the time elapsed (T) over a predefined number of events (n), mean of magnitudes $M_{\text {mean }}$ of last $n$ events, rate of release of energy $(\sqrt{d E})$, slope of the Guttenberg-Richter inverse power law curve (b-value), and magnitude between observed and expected events $(\Delta \mathrm{M})$. These indicators are summarized in Table I, where $\mathrm{T}$ represents the elapsed time between the time of an event with a certain threshold magnitude value $\left(t_{n}\right)$ and the time of the first event encountered $\left(t_{1}\right)$.

\section{E. Mathematical Model}

" $T$ " is the measure of the frequency of foreshocks based upon the threshold value selected for the magnitude. The larger $\mathrm{T}$ value indicates lack of foreshocks, which reveals the low probability of occurrence of some huge seismic event. The smaller " $T$ " value indicates the high possibility of forthcoming large seismic event calculated in (1)

$$
T=t_{n}-t_{1}
$$

" $\mathrm{M}_{\text {mean" }}$ represents the mean value of the earthquake magnitude calculated by dividing the cumulative mean with the total number of events $n$. As many types of magnitudes are in practice, we have calculated the cumulative magnitude value according to the Richter Scale (ML). It has been represented in Fig. 2, where magnitude ranges are given on $\mathrm{x}$-axis whereas frequency of events is plotted along y-axis. " $\mathrm{M}_{\text {mean }}$ " has been calculated in Table II by using (2)

$$
\mathrm{M}_{\text {mean }}=\frac{\sum \mathrm{M}_{i}}{n} .
$$


The seismic energy represented by " $\sqrt{ } \mathrm{dE}$ " is calculated by taking the square root of cumulative energy released in total number of events by the elapsed time $\mathrm{T}$, where $\mathrm{E}$ value has been calculated according to Gutenberg-Richter scale. Data about the seismic energy release are shown in Table III and the rate of release of energy calculated using (3)

$$
\sqrt{d \mathrm{E}}=\frac{\sqrt{\sum \mathrm{E}}}{\mathrm{T}},
$$

has been presented in the Fig. 3, where seismic quiescence for a long period of time has been observed. Longer seismic quiescence results in the storage of huge seismic energy, which can burst out abruptly causing a major earthquake.

b-value is an important measure in the earthquake prediction. b-value can be calculated by (4)

$$
\log _{10}(\mathrm{~N})=a-b \mathrm{M}
$$

Here "a" represents a variable, which is calculated from the cumulative frequency of seismic activity per year. "N" represents total number of events and "M" is the minimum magnitude observed.

Last indicator that is magnitude deficit " $\Delta \mathrm{M}$ " has a special impact on the data collection. It represents the difference between the observed magnitude of an event and the expected magnitude of an earthquake. Taking larger deficit indicates that micro event data have been ignored and macro event data are being considered. " $\Delta \mathrm{M}$ " can be calculated by (5)

$$
\Delta \mathrm{M}=\mathrm{M}_{\text {max_observed }}-\mathrm{M}_{\text {max_expected }} \text {. }
$$

Magnitude deficit and frequency of earthquakes per range have been presented in Table II.

Indicators given in Table I are basically some of the dimensions that could be used for earthquake prediction by our Fuzzy expert system. Moreover, other than mathematically calculated indicators, we have also considered the impact of some natural indicators in the earthquake magnitude prediction like rupture of the earth, the change in air temperature of the region, positions of the satellite for measuring ground motion, elevation in the ground-water level, impact of inverse wave and migration of animals and other insects from the region, etc.

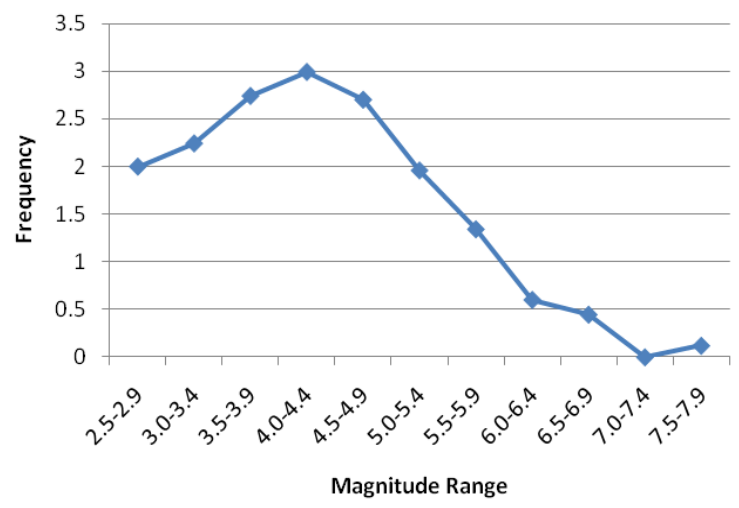

Fig. 2. Range of magnitude in relation to frequency.

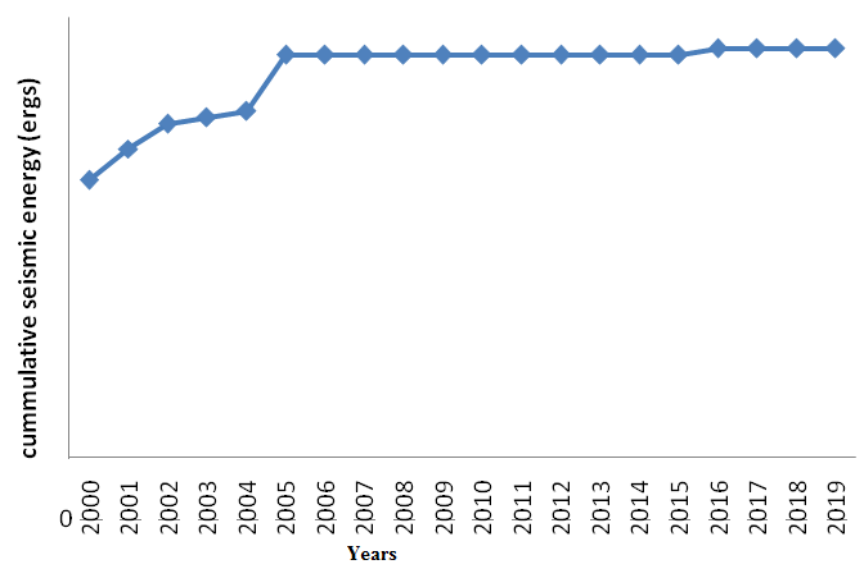

Fig. 3. Seismic energy released per year.

TABLE II. MAGNITUDE FREQUENCY (2000-2019).

\begin{tabular}{|c|c|c|c|}
\hline $\begin{array}{c}\text { Magnitude } \\
\text { range (M) }\end{array}$ & $\begin{array}{c}\text { Count per } \\
\text { range }\end{array}$ & $\begin{array}{c}\text { Frequency } \\
\mathbf{L o g}_{\mathbf{1 0}} \text { count }\end{array}$ & $\begin{array}{c}\text { Cumulative total } \\
\text { above lower min } \\
\text { range }\end{array}$ \\
\hline $2.5-2.9$ & 101 & 2.0 & 2432 \\
\hline $3.0-3.4$ & 175 & 2.243 & 2331 \\
\hline $3.5-3.9$ & 551 & 2.741 & 2156 \\
\hline $4.0-4.4$ & 982 & 2.992 & 1605 \\
\hline $4.5-4.9$ & 502 & 2.701 & 623 \\
\hline $5.0-5.4$ & 91 & 1.959 & 121 \\
\hline $5.5-5.9$ & 22 & 1.342 & 30 \\
\hline $6.0-6.4$ & 4 & 0.602 & 8 \\
\hline $6.5-6.9$ & 3 & 0.447 & 4 \\
\hline $7.0-7.4$ & 0 & 0 & 1 \\
\hline $7.5-7.9$ & 1 & 0 & 1 \\
\hline
\end{tabular}

Table A-I given in Appendix A-I presents the maximum and minimum earthquake magnitude that has been encountered per year during last two decades. This number has been used to calculate the maximum amount of seismic energy released during these events.

Maximum energy released per year as presented in the Table A-I has been shown graphically in Fig. 4, where it can be clearly observed that from 2005 until 2014 there was a seismic quiescence period. Then, after this long gap, in 2015, major earthquake of magnitude 7.5 has been encountered.

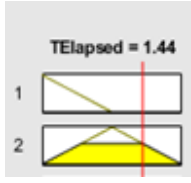

(a)

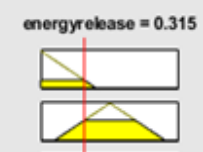

(b)

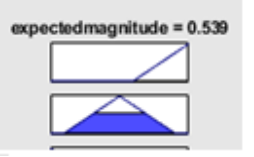

(c)
Fig. 4. The impact of (a) Rule 1, (b) Rule 2, and (c) Rule 5..

Table III presents those main parameters that were used to train Fuzzy interference system for future earthquake prediction. These parameters have been divided into two sets $\mathrm{x}$ and $\mathrm{y}$.

TABLE III. PARAMETERS USED TO TRAIN FES.

\begin{tabular}{|c|c|}
\hline $\begin{array}{c}\text { Set } \mathbf{x} \\
\text { (Direct parameters) }\end{array}$ & $\begin{array}{c}\text { Set } \mathbf{y} \\
\text { (Derived parameters) }\end{array}$ \\
\hline Longitude & Elapsed time \\
\hline Latitude & Mean magnitude \\
\hline Magnitude & Seismic Energy \\
\hline- & Slope \\
\hline- & Magnitude deficit \\
\hline
\end{tabular}




\section{F. Fuzzy Rules}

The parameters used to train FES have been divided into two sets. Critical situation may arise while deciding membership of an object as similar elements can partially belong to different sets and can create ambiguity in deciding membership to a particular set. Zadeh [35] has generated a crisp degree of membership with value between 0 and 1 . Here membership degree 1 represents completely belonging to a set and membership degree 0 represents do not belong to a set. The objects with the intermediate membership degree values belong partially to the same set. Five Fuzzy if-then rules have been applied on two input sets of parameters $\mathrm{x}$ and $\mathrm{y}$ to generate output using the proposed FES:

- Rule1: If a is $\mathrm{J}_{1}$ and $\mathrm{b}$ is $\mathrm{K}_{1}$, then $z_{1}=g_{1} a+h_{1} b+i_{1}$,

- Rule2: If a is $\mathrm{J}_{2}$ and $\mathrm{b}$ is $\mathrm{K}_{2}$, then $z_{2}=g_{2} a+h_{2} b+i_{2}$,

- Rule3: If $\mathrm{a}$ is $\mathrm{J}_{3}$ and $\mathrm{b}$ is $\mathrm{K}_{3}$, then $z_{3}=g_{3} a+h_{3} b+i_{3}$,

- Rule4: If $\mathrm{a}$ is $\mathrm{J}_{4}$ and $\mathrm{b}$ is $\mathrm{K}_{4}$, then $z_{4}=g_{4} a+h_{4} b+i_{4}$,

- Rule5: If $\mathrm{a}$ is $\mathrm{J}_{5}$ and $\mathrm{b}$ is $\mathrm{K}_{5}$, then $z_{5}=g_{5} a+h_{5} b+i_{5}$,

where $\mathrm{J}, \mathrm{K}$ are linguistic tags and $\mathrm{g}$, $\mathrm{h}$, and $\mathrm{i}$ are constants.

\section{G. Membership Functions}

Operations performed on every layer of proposed FES given in Fig. 1 has been illustrated as follows.

Layer 1 is the fuzzification layer. The parameters used to train FES in this layer have ambiguous characteristics. In order to obtain completeness, uniformity and consistency among these parameters, we have divided them into two Fuzzy subsets on the basis of their domain of change. In the first step, all variables are fuzzified to generate crisp variables. Fuzzification is done in the layer 1 of proposed FES. Every node $\mathrm{m}$ on this layer is a square node with node function presented in (6)

$$
l_{1, m}=\mu J_{m}(a)
$$

where $\mathrm{a}$ is the input for node $\mathrm{m}, \mathrm{J}_{\mathrm{m}}$ is the linguistic tag, which is based on the node function, $1_{1, \mathrm{~m}}$ is the membership function of $\mathrm{J}_{\mathrm{m}}$ to determine the rank for input " $\mathrm{a}$ " satisfying $\mathrm{J}_{\mathrm{m}} ; \mu$ is a gauss-shaped or bell-shaped with maximum and minimum equal to 1 and 0 with set of parameters $\left\{x_{m}, y_{m}\right.$, $Z_{m}$ \} calcculated in (7) and (8):

$$
\begin{aligned}
& \mu_{J_{m}}(x)=\frac{1}{\sqrt{1+\frac{a-z_{m}}{x_{m}}}} \times y_{m}, \\
& \mu_{k_{m}}(y)=\frac{1}{\sqrt{1+\frac{b-z_{m}}{y_{m}}}} \times y_{m} .
\end{aligned}
$$

Layer 2 performs Fuzzy AND operation. The firing strength of every rule has been calculated in this layer. Each node of FES acted as Fuzzy AND operator. On every node, a product of the result obtained from Fuzzy AND has been calculated for each rule to determine its firing strength calculated by (9)

$$
l_{2, m}=\mu_{J_{m}}(x) \times \mu_{k_{m}}(y)=\omega_{m}, \text { for } \mathrm{m}=1,2,3,4,5,
$$

where $\omega$ is the firing strength.

Layer 3 performs Normalization function. At this layer, the firing strength of every rule has been normalized by calculating the ratio of the firing strength of each rule with its total value as presented in (10)

$$
l_{3, m}=\frac{\omega_{m}}{\sum \omega_{m}}=\frac{\omega_{m}}{\omega_{1}+\omega_{2}+\omega_{3}+\omega_{4}+\omega_{5}}=\varpi_{m}, \text { for } \mathrm{m}=1,2,3,4,5
$$

where $\varpi$ is average firing strength.

Layer 4 is for Fuzzy inference of the result of pervious layers. At this layer, all participating variables have been systematically collected and passed to a model of Fuzzy conditional statements set $f$ to infer the results after applying multiple dependencies. We have applied the Mamdani interface system to specify the output of each rule as given in (11)

$$
l_{4, m}=\varpi_{m} \times f_{m}, \text { for } \mathrm{m}=1,2,3,4,5 .
$$

Layer 5 performs defuzzification of the Fuzzy result obtained from layer 4 . The output of layer 4 is in the form of Fuzzy sets. Defuzzification is necessary to calculate the deterministic value of every linguistic variable from set Y. The outputs $\left(f_{\text {out }}\right)$ of FES have been generated through layer 5 after the application of all rules and defuzzification function presented in (12)

$$
l_{5, m}=\sum \varpi \times f_{m}=f_{\text {out }} .
$$

\section{EXPERIMENTAL VERIFICATION}

In this study, Fuzzy expert system (FES) has been developed and seismic dataset of selected region has been used for training FES. We have used MATLAB software for experimental setup of FES. MATLAB is in the market since 1984. MATLAB has been used for implementations of the rulebase in multiple domains like signal processing, image processing, and automation, etc. It has multiple modules like Simulink, state flow, embedded coder, and Simulink coder. Simulink facilitates the model based development and code is automatically generated by the embedded coder. Moreover, through this software traceability of the code is much easier as compared to the legacy coding. Simulink facilitates researchers in the system development through block diagrams by providing many elements including transfer function, summing junction, function generators and oscilloscopes. We have used MATLAB to develop FES due to its debugging option that has gained the trust of the researchers from last thirty five years. 
FES developed in this study takes two inputs (x,y) and generates one output $(\mathrm{z})$. The input provided to FES could be direct seismic parameters (x) that represents the directly collected parameters from available seismic dataset and derived parameters ( $\mathrm{y}$ ) that have been obtained after performing some calculations on direct parameters. These inputs $\mathrm{x}, \mathrm{y}$ have to pass through membership function developed on the bases of rules defined by human expert to generate output z. Figure 4 describes the effect of Rules 1, 2, and 5 (given in Appendix A) on processing of input data through application of membership functions. In Fig. 4, time elapsed since an earthquake has not occurred is shown in (a) and the energy released is shown in (b). The rules have been applied to these two inputs indicating the high value of time elapsed in relation to the low value of energy released over time, so the output variable $\mathrm{z}$ is representing high value of magnitude of the next earthquake given in Fig. 4(c).

Relationship of energy released with time elapsed has been shown by the surface graph presented in Fig. 5. It shows that if the energy released is low and elapsed time is higher, then, expected magnitude would also have high value.

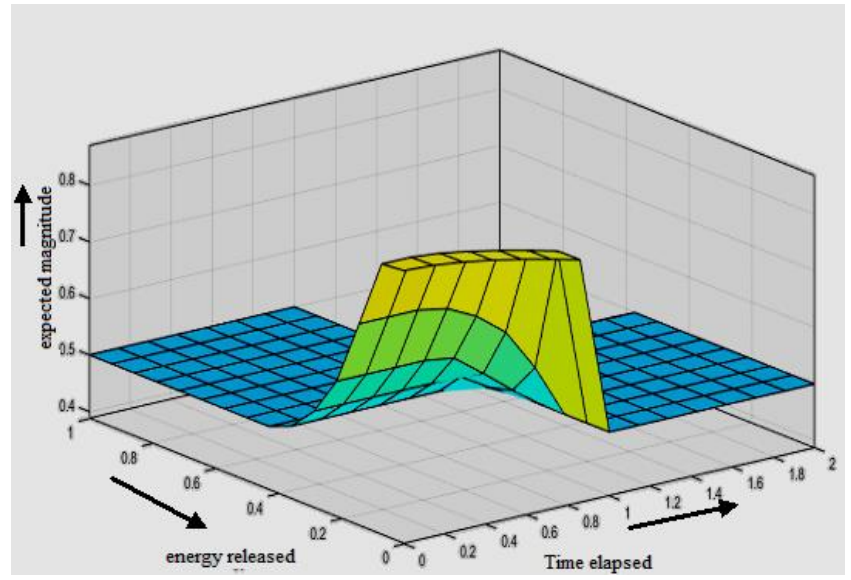

Fig. 5. Relationship of energy released and expected magnitude over time.

The relationship between depth and rupture length has been shown in Fig. 6. It is based on the rule that if more magnitude has been encountered, then the depth will be near to the crust. Figure 6 presents low value of depth in relation with high value of rupture. Then, the resultant magnitude expected is high. The impact of rules shown in Fig. 6 has been presented by the surface graph given in Fig. 7. It presents that if more energy is released, then the earthquake depth will be shallow and will cause larger rupture.

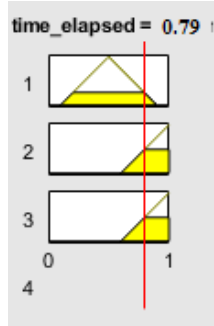

(a)

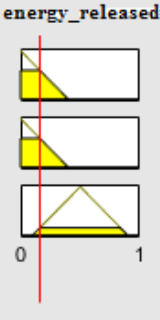

(b)

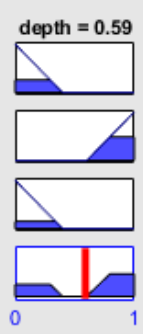

(c)

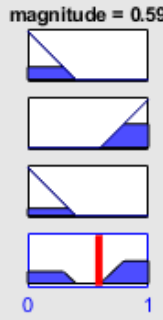

(d)

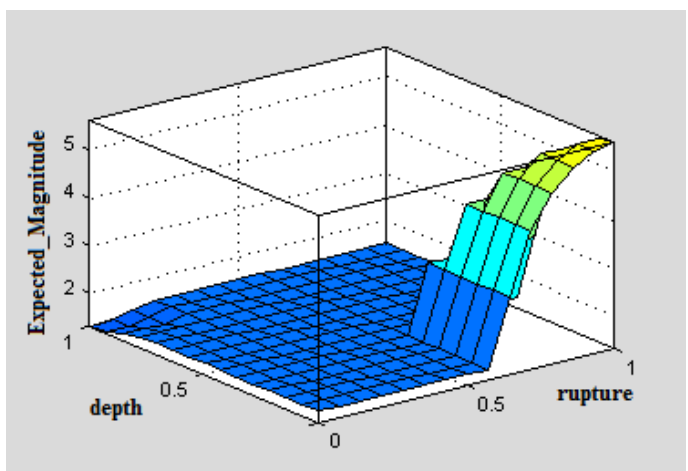

Fig. 7. Relationship of depth and rupture length over magnitude.

The relationship among elapsed time and depth in relation to expected magnitude has been shown in Fig. 8. It is based on the rule that if more time has been elapsed since an earthquake has been encountered, then more magnitude of future earthquake event is expected with low depth.

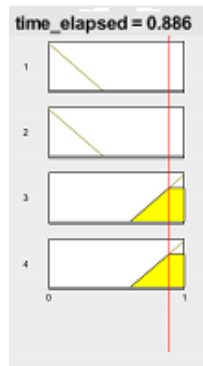

(a)

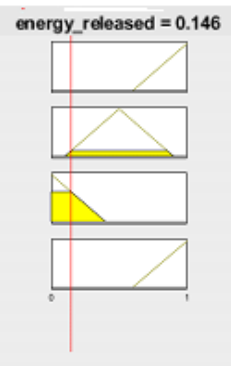

(b)

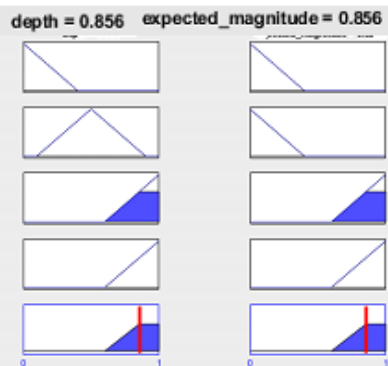

(c)

(d)
Fig. 8. The impact of Rule 7.

The impact of time elapsed since an earthquake has not encountered and expected magnitude in relation to the expected depth have been presented in Fig. 9.

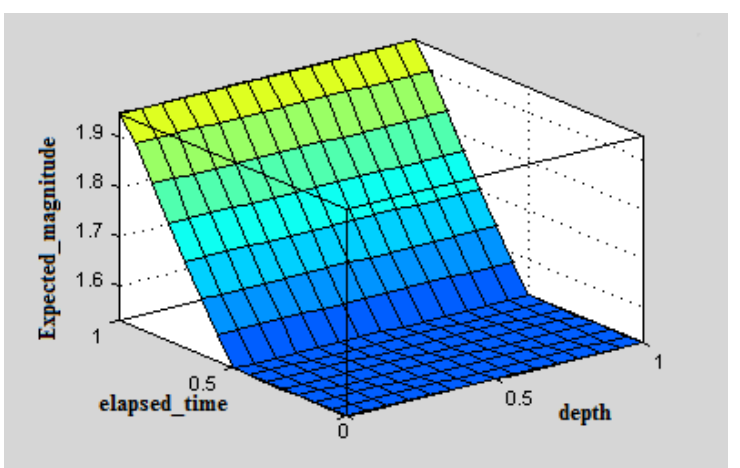

Fig. 9. Relationship between time elapsed and expected magnitude over depth.

\section{RESULTS AND DISCUSSION}

The data from the sources mentioned in Section III have been used to train FES. Dataset provides the values for direct parameters like date, longitude, latitude, and magnitude. Formulas mentioned in Section III have been applied to derive other parameters like mean magnitude, rupture length, time elapsed, energy released, etc. we have applied Fuzzy Inference System (FIS) to determine the expected magnitude of an upcoming earthquake. The basic structure of FIS is given in Fig. 10. 


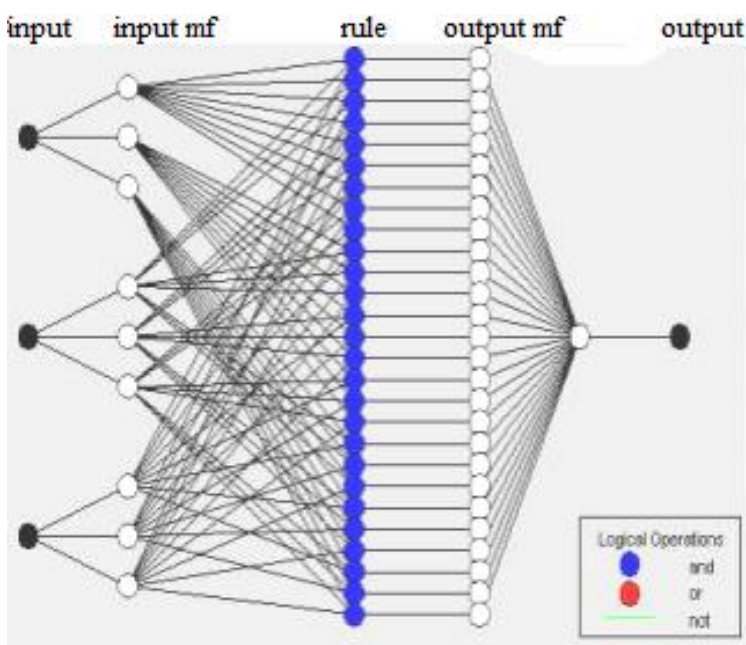

Fig. 10. Structure of Fuzzy Inference System (FIS).

It maps input parameters to the input membership function. Membership functions are then mapped to the set of rules. These rules are mapped to the set of output parameters, which are further mapped to output membership function, which is finally mapped to the final output membership function to generate single valued output indicating the decision.

From the given dataset, Adaptive Neuro-Fuzzy Inference System (ANFIS) constructs a FIS, whose membership functions are tuned to learn from the dataset being fed using back propagation algorithm with the least squared method. During learning process, parameters associated to the membership function change accordingly. Gradient vector is used to determine the degree of correctness in modelling input into output data over a given set of parameters.

After obtaining gradient vector, parameters are optimized to reduce the error rate (err). Error is obtained by calculating sum of square difference among actual and desired outputs. Figure 10 presents the ANFIS structure, which shows that rules have been developed using AND, OR or NOT clauses. Leftmost nodes were used to receive input whereas output is produced on leftmost nodes. Figure 11 presents training data and Fig. 12 presents the output obtained from FIS.

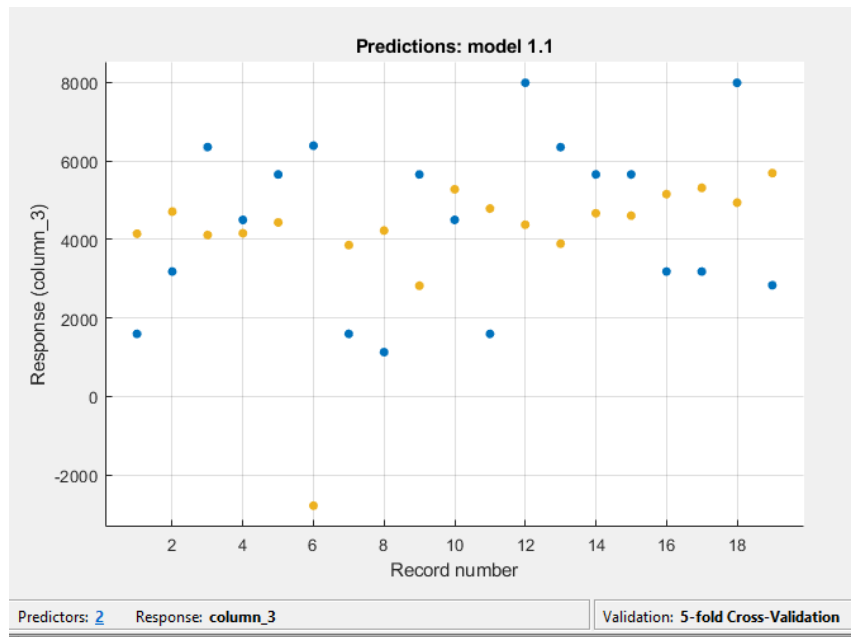

Fig. 11. Training data.

Prediction model 1.1 given in Fig. 11 presents the plot of actual earthquake events against the predicted events. We have used 5-fold cross validation technique to maintain accuracy while mapping actual events against the predictions of FIS. Figure 12 presents the gradient vector indicating the degree of actual response (occurrence of actual seismic event) against the predicted response of FIS. It has been observed from Fig. 12 that $47 \%$ of true responses have matched with the predicted ones.

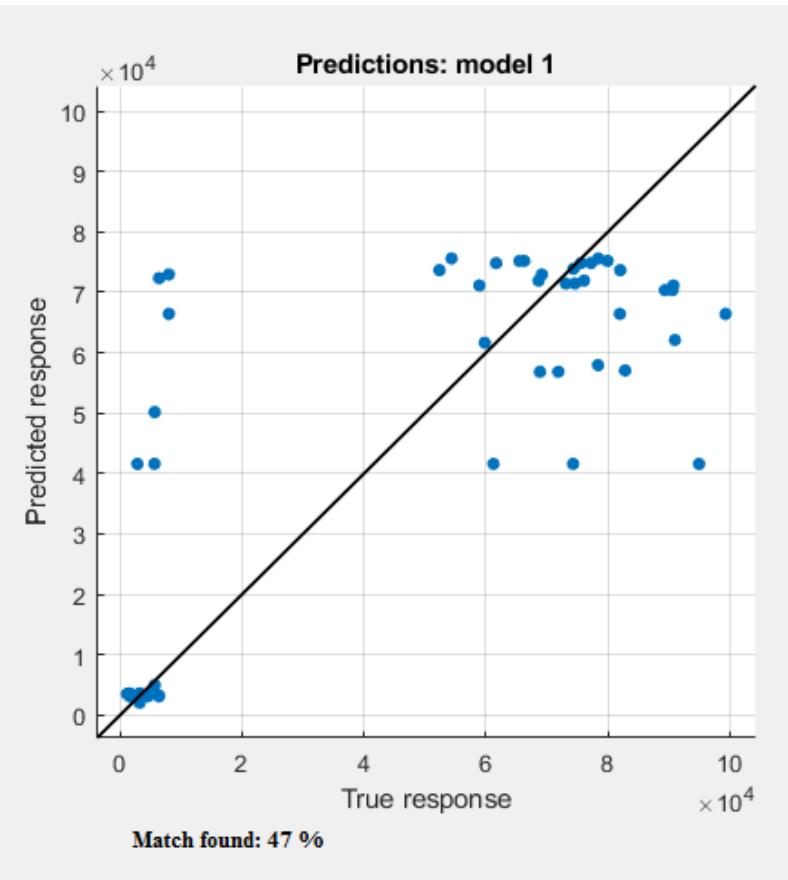

Fig. 12. Output of FIS.

The error of training FIS has been presented in Fig. 13. To calculate error in prediction, the output predicted by the proposed system has been converted at Richter scale and subtracted from instrumentally recorded value.

Magnitude error $=$ recorded value - FIS predicted value .

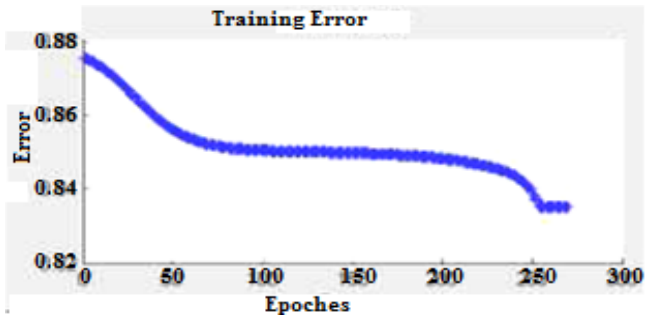

Fig. 13. Training error.

In this research, parameters have been optimized through combination of back propagation algorithm along with least square method (LSM). Zero error tolerance with training stopping point at 270 epochs have been used. It was used to stop training of dataset until error rate remain within tolerance value that have converged to 0.83 . Figure 14 presents the results after successful training of ANFIS at error tolerance rate of 0.83 .

The graph presented in Fig. 14 clearly indicates the true response of the trained prediction model in relation to the residual events. It is clear from the Fig. 14 that ANFIS is successful to train all earthquake data and is successfully predicting $47 \%$ of instrumentally recorded earthquake events to error convergence of 0.83 . 


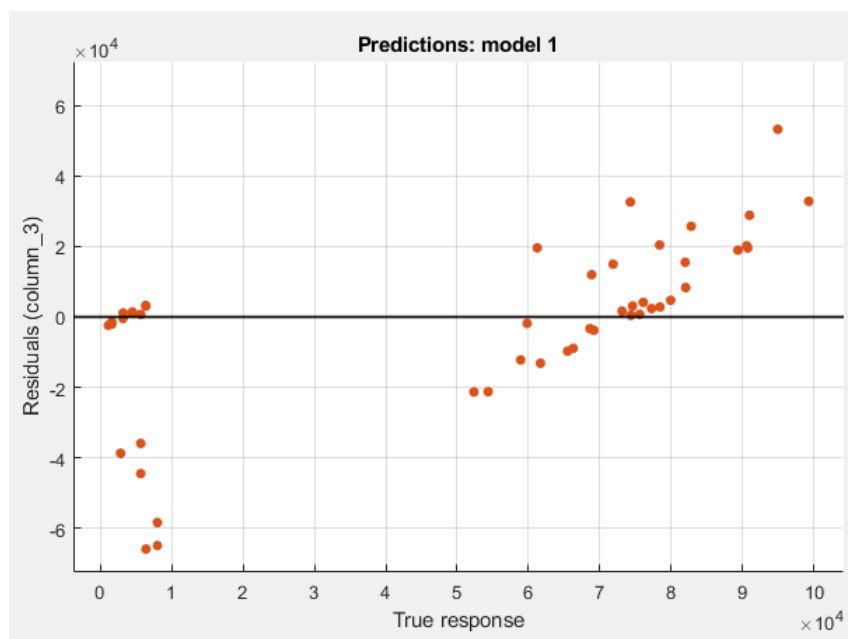

Fig. 14. FIS Output at error tolerance value 0.83 .

\section{CONCLUSIONS}

In this research, Fuzzy expert system for earthquake prediction has been presented. Data have been obtained from USGS, ISI, and Seismic centre Tarbela dam for $100 \mathrm{~km}$ radial area around the reference point of $34.708^{\circ} \mathrm{N}$, $72.5478^{\circ}$ E. Multiple parameters have been calculated from dataset, which are further passed to Fuzzy system as inputs. Membership functions have been developed after application of multiple rules prescribed by human expert. In this research, mathematical model has been presented and its implementation along with experimental verification has been performed using MATLAB software. Fuzzy inference system has been developed to ensure the accuracy of the proposed FES. Seismic data of the selected region have been passed to the FIS as training dataset that went through multiple comparisons to generate the prediction model. A comprehensive view of true values of earthquake events against the predicted values has been presented. Hence, the output of FIS has been obtained after passing dataset through multiple layers of the proposed system. It has been observed that the proposed system is capable enough to predict the earthquakes with $47 \%$ accuracy with 0.83 error tolerance. We intend to apply more advanced techniques like machine learning on the same dataset for earthquake prediction in future.

\section{APPENDIX A}

Rule 1: $\mathrm{M} \infty \mathrm{E}$ magnitude expected is directly proportional to energy released. If the magnitude of the earthquake is larger, then it has released a lot of energy. If there is no earthquake event from some period, then a lot of energy is being accumulated, which may cause a catastrophic earthquake with bigger magnitude.

Rule 2: $\mathrm{T} \infty \mathrm{E}$ time elapsed is directly proportional to energy released. If for a longer time period no earthquake event has been encountered, then the seismic energy stored would be higher.

Rule 3: b-value (slope) is directly proportional to the frequency of earthquakes.

Rule 4: Increased b-value after quiescence in energy released is directly proportional to expected magnitude.

Rule 5: If time elapsed is longer and energy released is low, then expected earthquake magnitude would be higher.

Rule 6: If time elapsed is longer and energy released is low, then expected depth could be shallow.

Rule 7: If time elapsed is longer and energy released is low, then expected rupture would be longer.

\begin{tabular}{|c|c|c|c|c|}
\hline Year & $\begin{array}{l}\text { Minimum } \\
\text { magnitude }\end{array}$ & $\begin{array}{c}\text { Peak } \\
\text { recorded } \\
\text { magnitude }\end{array}$ & $\begin{array}{c}\text { Seismic } \\
\text { Energy } \\
\text { Released(ergs) }\end{array}$ & $\begin{array}{c}\text { Cumulative } \\
\text { energy } \\
\left(\mathrm{ergs} * 10^{12}\right)\end{array}$ \\
\hline 2000 & 3.7 & 5.2 & $1.577 \times 10^{12}$ & 1.577 \\
\hline 2001 & 3.6 & 5.4 & $3.147 \times 10^{12}$ & 4.724 \\
\hline 2002 & 3.4 & 5.6 & $6.279 \times 10^{12}$ & 11.003 \\
\hline 2003 & 3.5 & 5.5 & $4.446 \times 10^{12}$ & 15.447 \\
\hline 2004 & 3.5 & 4.9 & $5.597 \times 10^{11}$ & 16.0087 \\
\hline 2005 & 2.9 & 7.6 & $6.297 \times 10^{15}$ & 6313.0087 \\
\hline 2006 & 3.2 & 5.2 & $1.577 \times 10^{12}$ & 6314.5857 \\
\hline 2007 & 3.4 & 5.1 & $1.117 \times 10^{12}$ & 6315.7027 \\
\hline 2008 & 3.3 & 4.9 & $5.597 \times 10^{11}$ & 6316.2624 \\
\hline 2009 & 4.0 & 5.5 & $4.446 \times 10^{12}$ & 6320.7084 \\
\hline 2010 & 4.0 & 5.2 & $1.577 \times 10^{12}$ & 6322.2854 \\
\hline 2011 & 4.0 & 5.0 & $7.906 \times 10^{11}$ & 6323.076 \\
\hline 2012 & 4.0 & 5.6 & $6.279 \times 10^{12}$ & 6329.355 \\
\hline 2013 & 4.0 & 4.9 & $5.597 \times 10^{11}$ & 6329.9147 \\
\hline 2014 & 3.9 & 4.9 & $5.597 \times 10^{11}$ & 6330.4744 \\
\hline 2015 & 4.0 & 5.4 & $3.147 \times 10^{12}$ & 6333.6214 \\
\hline 2016 & 4.1 & 5.4 & $3.147 \times 10^{12}$ & 6336.7684 \\
\hline 2017 & 4.2 & 5 & $7.906 \times 10^{11}$ & 6337.559 \\
\hline 2018 & 3.9 & 4.7 & $2.805 \times 10^{11}$ & 6337.8395 \\
\hline 2019 & 4.0 & 5.2 & $1.572 \times 10^{12}$ & 6339.4115 \\
\hline
\end{tabular}

\section{ACKNOWLEDGMENT}

The authors appreciate the anonymous reviewers for their valuable feedback on the initial version of this paper. We are thankful to Seismic Center, Tarbela dam, Pakistan for providing us seismic data. We are also thankful to Ms. Rameen Faisal for her valuable feedback on this paper.

\section{CONFLICTS OF INTEREST}

The authors declare that they have no conflicts of interest.

\section{REFERENCES}

[1] R. Tehseen, M. S. Farooq, and A. Abid, "Earthquake prediction using expert systems: A systematic mapping study”, Sustainability, vol. 12, no. 6 , p. 2420,2020 . DOI: $10.3390 /$ su12062420.

[2] A. D. K. Tareen, K. M. Asim, K. J. Kearfott, M. Rafique, M. S. A Nadeem, T. Iqbal, and S. U. Rahman, "Automated anomalous behaviour detection in soil radon gas prior to earthquakes using computational intelligence techniques", Journal of environmental radioactivity, vol. 203, pp. 48-54, 2019. DOI: 10.1016/j.jenvrad.2019.03.003.

[3] C. Polykretis, C. Chalkias, and M. Ferentinou, "Adaptive neuro-fuzzy inference system (ANFIS) modeling for landslide susceptibility assessment in a Mediterranean hilly area", Bulletin of Engineering Geology and the Environment, vol. 78, no. 2, pp. 1173-1187, 2019. DOI: 10.1007/s10064-017-1125-1.

[4] M. Razifard, G. Shoaei, and M. Zare, "Application of fuzzy logic in the preparation of hazard maps of landslides triggered by the twin Ahar-Varzeghan earthquakes (2012)", Bulletin of Engineering 
Geology and the Environment, vol. 78, no. 1, pp. 223-245, 2019. DOI: $10.1007 / \mathrm{s} 10064-018-1235-4$.

[5] M. G. D’Urso, D. Masi, G. Zuccaro, and D. De Gregorio, "Multicriteria fuzzy analysis for a GIS-based management of earthquake scenarios", Computer-Aided Civil and Infrastructure Engineering, vol. 33, no. 2, pp. 165-179, 2018. DOI: 10.1111/mice.12335.

[6] W. Cai, L. Dou, M. Zhang, W. Cao, J. Q. Shi, and L. Feng, "A fuzzy comprehensive evaluation methodology for rock burst forecasting using microseismic monitoring", Tunnelling and Underground Space Technology, vol. 80, pp. 232-245, 2018. DOI: 10.1016/j.tust.2018.06.029.

[7] S. Ghorbani, M. Barari, and M. Hoseini, "Presenting a new method to improve the detection of micro-seismic events", Environmental monitoring and assessment, vol. 190, no. 8, pp. 1-13, 2018. DOI: 10.1007/s10661-018-6837-6.

[8] O. Ghorbanzadeh, H. Rostamzadeh, T. Blaschke, K. Gholaminia, and J. Aryal, "A new GIS-based data mining technique using an adaptive neuro-fuzzy inference system (ANFIS) and k-fold cross-validation approach for land subsidence susceptibility mapping", Natural Hazards, vol. 94, no. 2, pp. 497-517, 2018. DOI: 10.1007/s11069018-3449-y.

[9] N. G. Tosunoğlu and A. Apaydın, "A new spatial algorithm based on adaptive fuzzy neural network for prediction of crustal motion velocities in earthquake research", International Journal of Fuzzy Systems, vol. 20, no. 5, pp. 1656-1670, 2018. DOI: $10.1007 / \mathrm{s} 40815-$ 018-0483-6.

[10] M. S. Hossain, A. Al Hasan, S. Guha, and K. Andersson, "A belief rule based expert system to predict earthquake under uncertainty", Journal of Wireless Mobile Networks, Ubiquitous Computing, and Dependable Applications, vol. 9, no. 2, pp. 26-41, 2018. DOI 10.22667/JOWUA.2018.06.30.026.

[11] K. M. Asim, F. Martínez-Álvarez, A. Basit, and T. Iqbal, "Earthquake magnitude prediction in Hindukush region using machine learning techniques", Natural Hazards, vol. 85, no. 1, pp. 471-486, 2017. DOI: $10.1007 / \mathrm{s} 11069-016-2579-3$.

[12] M. Ahmadi, A. Nasrollahnejad, and A. Faraji, "Prediction of peak ground acceleration for earthquakes by using intelligent methods", in Proc. of 2017 5th Iranian Joint Congress on Fuzzy and Intelligent Systems (CFIS), 2017, pp. 7-12. DOI: 10.1109/CFIS.2017.8003588.

[13] B. T. Pham, D. T. Bui, H. V. Pham, H. Q. Le, I. Prakash, and M. B. Dholakia, "Landslide hazard assessment using random subspace fuzzy rules based classifier ensemble and probability analysis of rainfall data: A case study at Mu Cang Chai District, Yen Bai Province (Viet Nam)", Journal of the Indian Society of Remote Sensing, vol. 45, no. 4, pp. 673-683, 2017. DOI: $10.1007 / \mathrm{s} 12524$ 016-0620-3.

[14] K. M. Asim, M. Awais, F. Martínez-Álvarez, and T. Iqbal, "Seismic activity prediction using computational intelligence techniques in northern Pakistan", Acta Geophysica, vol. 65, no. 5, pp. 919-930. DOI: 10.1007/s11600-017-0082-1.

[15] D. V. Ratnam, G. Vindhya, and J. K. Dabbakuti, "Ionospheric forecasting model using fuzzy logic-based gradient descent method", Geodesy and Geodynamics, vol. 8, no. 5, pp. 305-310, 2017. DOI: 10.1016/j.geog.2017.05.003.

[16] R. S. Kamath and R. K. Kamat, "Earthquake magnitude prediction for Andaman-Nicobar islands: Adaptive neuro fuzzy modeling with fuzzy subtractive clustering approach", Journal of Chemical and Pharmaceutical Sciences (JCHPS), vol. 10, no. 3, pp. 1225-1230, 2017.

[17] J. M. Andrić and D. G. Lu, "Fuzzy methods for prediction of seismic resilience of bridges", International Journal of Disaster Risk Reduction, vol. 22, pp. 458-468, 2017 DOI: 10.1016/j.ijdrr.2017.01.001.

[18] A. Andalib, M. Zare, and F. Atry, "A fuzzy expert system for earthquake prediction, case study: The Zagros range", in Proc. of the $3^{r d}$ International Conference on Modeling, Simulation and Applied Optimization, UAE, 2009, pp. 1-4.

[19] I. N. Aghdam, M. H. M. Varzandeh, and B. Pradhan, "Landslide susceptibility mapping using an ensemble statistical index (Wi) and adaptive neuro-fuzzy inference system (ANFIS) model at Alborz Mountains (Iran)", Environmental Earth Sciences, vol. 75, no. 7, 2016. DOI: 10.1007/s12665-015-5233-6.

[20] A. Ahumada, A. Altunkaynak, and A. Ayoub, "Fuzzy logic-based attenuation relationships of strong motion earthquake records", Expert Systems with Applications, vol. 42, no. 3, pp. 1287-1297, 2015. DOI: 10.1016/j.eswa.2014.09.035.

[21] E. S. Akhouayri, D. Agliz, D. Zonta, and A. Atmani, "A fuzzy expert system for automatic seismic signal classification", Expert Systems with Applications, vol. 42, no. 3, pp. 1013-1027, 2015. DOI 10.1016/j.eswa.2014.08.023

[22] V. M. Torres and O. Castillo, "A type-2 fuzzy neural network ensemble to predict chaotic time series", in Design of Intelligent Systems Based on Fuzzy Logic, Neural Networks and Nature Inspired Optimization. Springer, Cham, 2015, pp. 185-195. DOI 10.1007/978-3-319-17747-2 15 .

[23] N. Tahernia, "Fuzzy-logic tree approach for seismic hazard analysis", IACSIT International Journal of Engineering and Technology, vol. 6, no. 3, pp. 182-185, 2014. DOI: 10.7763/IJET.2014.V6.692.

[24] A. Ikram and U. Qamar, "A rule-based expert system for earthquake prediction", Journal of Intelligent Information Systems, vol. 43, no. 2, pp. 205-230, 2014. DOI: 10.1007/s10844-014-0316-5.

[25] M. Mirrashid, "Earthquake magnitude prediction by adaptive neurofuzzy inference system (ANFIS) based on fuzzy C-means algorithm", Natural hazards, vol. 74 , no. 3, pp. 1577-1593, 2014. DOI 10.1007/s11069-014-1264-7.

[26] S. S. Sengar, A. Kumar, S. K. Ghosh, H. R. Wason, P. L. N. Raju, and Y. K. Murthy, "Earthquake-induced built-up damage identification using fuzzy approach", Geomatics, Natural Hazards and Risk, vol. 4, no. 4, pp. 320-338, 2013. DOI: 10.1080/19475705.2012.746242.

[27] H. R. Pourghasemi, B. Pradhan, and C. Gokceoglu, "Application of fuzzy logic and analytical hierarchy process (AHP) to landslide susceptibility mapping at Haraz watershed, Iran", Natural hazards, vol. 63, no. 2, pp. 965-996, 2012. DOI: 10.1007/s11069-012-0217-2.

[28] S. Mohsin and F. Azam, "Computational seismic algorithmic comparison for earthquake prediction", International Journal of Geology, vol. 5, no. 3, pp. 53-59, 2011.

[29] B. Pradhan, "Use of GIS-based fuzzy logic relations and its cross application to produce landslide susceptibility maps in three test areas in Malaysia", Environmental Earth Sciences, vol. 63, no. 2, pp. 329349, 2011. DOI: $10.1007 / \mathrm{s} 12665-010-0705-1$.

[30] M. Shibli, "A novel approach to predict earthquakes using adaptive neural fuzzy inference system and conservation of energy-angular momentum", Inter. J. Comp. Inf. Sys. Ind. Manag. Appli., vol. 3, pp. 371-390, 2011

[31] D. Sun and B. Sun, "Rapid prediction of earthquake damage to buildings based on fuzzy analysis", in Proc. of 2010 Seventh International Conference on Fuzzy Systems and Knowledge Discovery, 2010, vol. 3, pp. 1332-1335. DOI 10.1109/FSKD.2010.5569101.

[32] T. F. Gu and J. D. Wang, "Application of fuzzy neural networks for predicting seismic subsidence coefficient of loess subgrade", in Proc. of 2010 Sixth International Conference on Natural Computation, 2010, vol. 3, pp. 1556-1559. DOI: 10.1109/ICNC.2010.5583718.

[33] Sh. Wang, H. Liu, Sh. Wang, S. Tong, and R. Wang, "Pseudoacoustic inversion method and its application", in Proc. of 2010 Seventh International Conference on Fuzzy Systems and Knowledge Discovery, 2010, vol. 2, pp. 598-601. DOI: 10.1109/FSKD.2010.5569460.

[34] A. Azadeh, I. M. Fam, M. Khoshnoud, and M. Nikafrouz, "Design and implementation of a fuzzy expert system for performance assessment of an integrated health, safety, environment (HSE) and ergonomics system: The case of a gas refinery", Information Sciences, vol. 178 , no. 22 , pp. $4280-4300,2008$. DOI 10.1016/j.ins.2008.06.026

[35] L. A. Zadeh, "Fuzzy sets", Information and control, vol. 8, no. 3, pp. 338-353, 1965. DOI: 10.1016/S0019-9958(65)90241-X. 